\title{
The mechanism of ageing: primary role of transposable elements in genome disintegration
}

\author{
Ádám Sturm ${ }^{1} \cdot$ Zoltán Ivics $^{2} \cdot$ Tibor Vellai $^{1}$
}

Received: 6 May 2014/Revised: 16 March 2015/Accepted: 25 March 2015/Published online: 3 April 2015

(C) Springer Basel 2015

\begin{abstract}
Understanding the molecular basis of ageing remains a fundamental problem in biology. In multicellular organisms, while the soma undergoes a progressive deterioration over the lifespan, the germ line is essentially immortal as it interconnects the subsequent generations. Genomic instability in somatic cells increases with age, and accumulating evidence indicates that the disintegration of somatic genomes is accompanied by the mobilisation of transposable elements (TEs) that, when mobilised, can be mutagenic by disrupting coding or regulatory sequences. In contrast, TEs are effectively silenced in the germ line by the Piwi-piRNA system. Here, we propose that TE repression transmits the persistent proliferation capacity and the non-ageing phenotype (e.g., preservation of genomic integrity) of the germ line. The Piwi-piRNA pathway also operates in tumorous cells and in somatic cells of certain organisms, including hydras, which likewise exhibit immortality. However, in somatic cells lacking the PiwipiRNA pathway, gradual chromatin decondensation increasingly allows the mobilisation of TEs as the organism ages. This can explain why the mortality rate rises exponentially throughout the adult life in most animal species, including humans.
\end{abstract}

Zoltán Ivics

zoltan.ivics@pei.de

$\triangle$ Tibor Vellai

vellai.tibor@gmail.com;

vellai@falco.elte.hu

1 Department of Genetics, Eötvös Loránd University, Pázmány Péter stny. 1/C, Budapest, Hungary

2 Division of Medical Biotechnology, Paul Ehrlich Institute, 63225 Langen, Germany
Keywords Lifespan determination .

Age-related diseases · Retroelements .

Repetitive sequences $\cdot$ Chromatin relaxation .

Non-coding small RNAs $\cdot$ Methylation · Cancer

\section{Introduction}

Understanding what actually causes ageing remains admittedly a fundamental and fascinating problem in biology [1]. Experimental data accumulated in the last three decades have led to the identification of various environmental and genetic factors, as well as chemical substances that influence lifespan in divergent eukaryotic species $[1,2]$. Organisms normally age faster and hence live shorter under stress conditions that can lead to the generation of DNA mutations and, often as a consequence of mutations, damaged cytoplasmic constituents (including injured proteins, lipids, carbohydrates and organelles). Such types of damage can interfere with cellular functioning; thereby, they should be eliminated by effective repair and self-cleaning mechanisms to maintain cellular homeostasis. These mechanisms include DNA repair pathways, molecular chaperons, as well as the proteasome-ubiquitin system and lysosome-mediated autophagy, the main forms of cellular self-degradation [3]. This has led to the attractive model that the gradual, lifelong accumulation of unrepaired cellular damage drives the ageing process and determines the incidence of age-related fatal diseases $[4,5]$.

However, some observations contradict certain aspects of this damage-driven model of ageing. First, mutations should appear exponentially during the lifespan if they are to explain mortality patterns apparent at advanced ages (mortality rates often rise exponentially 
throughout adult life) [6]. Environmental and metabolic stress factors causing mutations, however, appear to be nearly constant during lifespan in any species examined. Thus, the causal role of mutations in the ageing process remains largely unclear [6]. Second, in the nematode Caenorhabditis elegans lowering mitochondrial respiration during adulthood only does not affect lifespan, even though it lowers the amount of cellular damage that are caused by reactive oxygen species generated during respiration [7]. Third, mice defective for $P m s 2$, a DNA mismatch repair gene, display a 100 -fold elevation in mutation frequency and a dramatically increased cancer rate, while not exhibiting an accelerated ageing phenotype [8]. One can argue that the early death stemming from the increased prevalence of cancer in Pms 2 mutant animals may be masking the signs of accelerated ageing [9]. However, C. elegans strains deficient in $m s h-2$, another mismatch repair gene, have a lifespan identical to that of the wild type [10], and the soma of this organism is known to be devoid of cancer. It is also possible that many ageing phenotypes could be caused by genome rearrangements and not by point mutations [9]. Nevertheless, these examples show that the rate of ageing cannot be lowered by merely increasing the effectiveness of cellular repair mechanisms or diminishing the severity of factors responsible for damage. It may, therefore, be inferred that ageing is primarily caused by factors that are beyond the capabilities of cellular repair mechanisms.

Another attractive model of ageing is formulated by the "telomere shortening theory" [11]. The activity of the telomerase enzyme complex responsible for maintaining the structure of the chromosome ends (telomeres) at each round of cell division likewise affects lifespan in a number of model organisms [11, 12]. Still, the ageing process of postmitotic cells (like neurons) contradicts the theory. Furthermore, the somatic cells of adult $C$. elegans do not divide, meaning that the shortening of telomeric regions is not an issue even in the case of a complete absence of telomerase activity [13]. Regardless, the adult nematode ages and dies in about 2 weeks. Thus, the effect of telomere length on ageing appears to be rather complex.

Unlike the soma, the germ line shows no sign of ageing. What is it that renders the germ line potentially immortal? The question is relevant as its cells also display metabolism and respond to diverse molecular and environmental stress factors. And how can certain organisms (such as certain hydras and the jellyfish Turritopsis nutricula) be immortal, when the above features define their somatic cells as well?

\section{Age-related differences in genomic integrity between somatic and germ line cells}

In most eukaryotic organisms, the genome of somatic cells progressively accumulates mutations, mostly genomic rearrangements, as the individual ages [14-16]; whereas the integrity of genetic material in germ line cells remains largely stable (the latter could result from either selection against mutations-damaged embryos just die at early stages-or a decreased mutation rate [14-16]). This suggests that uncovering the causes of this difference between the stability of the genetic information of these two cell types may help to understand the mechanisms that are actually responsible for ageing. This view is supported by a recent discovery of ectopic expression of germ line-specific genes in the soma of long-lived insulin/IGF-1 signallingdefective nematodes [16]. The longer lifespan can thus be characterised by soma-to-germ line transformation of cell fate.

The eukaryotic genome is organised into a highly ordered chromatin structure composed of DNA and histone proteins. Different regions of the genome exist in either the relatively loose euchromatin or tightly packaged heterochromatin state. The former represents transcriptionally active domains, while the latter represents transcriptionally silent chromosomal regions. Histone proteins can be covalently modified at specific amino acid side chains to modify gene expression. Hallmark features of heterochromatin formation include, for example, histone hypoacetylation, H3K9 (histone protein H3 lysine-9) hypermethylation, and recruitment of heterochromatin protein 1 (HP1) [17]. In the soma, heterochromatin domains established early in embryogenesis are progressively broken down during ageing [18, 19]. This age-associated gradual loss of heterochromatin contributes to the derepression of silenced genes at the affected loci. Although heterochromatization at specific loci can also occur, ageing is associated with an overall net decrease in heterochromatin state in somatic cells [18, 19]. Indeed, overexpression of HP1 that promotes chromatin condensation extends lifespan in the fruit fly Drosophila melanogaster [20]. Genetic data indicate that longevity response triggered by caloric restriction is tightly coupled to the modification of heterochromatic domains in the somatic genome [21]. Furthermore, DNA methylation at the 5 position of cytosine (5-methylcytosine) also leads to epigenetic repression of gene expression, and markedly decreases as the organism ages (with an overall decrease in methylcytosine content, but with local increases in some cytosine guanine dinucleotide- $\mathrm{CpG}-$ islands) [22]. This phenomenon cannot be observed in immortal cell lines 
$[23,24]$. Hence, another common molecular feature associated with ageing is the global hypomethylation of genomic DNA [25].

Loss of heterochromatin structure and hypomethylation allow for the activation and relocation of transposable elements (TEs) that constitute a significant part of eukaryotic genomes ( $>45 \%$ of the human genome consist of TEs [26-28]. For example, a progressive decline in DNA methylation during ageing preferentially takes place in TE-derived repetitive elements dispersed throughout the genome [29]. Mobilisation of TEs can lead to genomic instability: if a TE jumps into a functional (coding or regulatory) region of the genome, the insertion often results in loss of function, thereby, facilitating the death of the affected cell. The mass occurrence of transposition events can lead to various degenerative processes [30].

\section{TEs, their mobilisation and silencing}

TEs can be divided into two main groups, DNA transposons and retrotransposons [31]. DNA transposons are DNA stretches that encode an enzyme called transposase. In a so-called cut-and-paste transposition mechanism, the transposase binds to the inverted repeat sequences found at the ends of the transposon, and slices the DNA at these sites. The sliced DNA fragment is then integrated into a new genomic locus by the transposase.

Retrotransposons can be subdivided into two subgroups, retrotransposons with long terminal repeats (LTR retrotransposons) and without LTR (non-LTR retrotransposons). LTR retrotransposons are widely distributed in eukaryotes, and make up nearly $8 \%$ of the human genome [28]. Non-LTR retrotransposons are the most abundant TEs in mammals, represented by the long and short interspersed nuclear elements (LINEs and SINEs). Retrotransposons can mobilise themselves through an element-derived RNA intermediate, which is converted into a complementary DNA (cDNA) by reverse transcription, followed by integration into a new genomic locus, thereby generating a second copy of the TE (copy-and-paste mechanism).

Since TEs serve as potent mutagenic factors causing genomic instability, organisms have evolved diverse molecular mechanisms to protect their genomes against TE activity [32]. Defects in these mechanisms can cause sterility and accelerated ageing. One of the main mechanisms blocking the movement of TEs is RNA-induced posttranscriptional gene silencing, during which small RNA molecules-small interfering RNAs (siRNAs) and Piwi (P-element induced wimpy testis in Drosophila) protein-interacting RNAs (piRNAs) - mediate the degradation of TE transcripts (Fig. 1). In the siRNA pathway, a
TE transcript-derived double-stranded RNA (dsRNA) is cleaved into 20-22 nucleotide-long siRNA fragments by the enzyme Dicer, an endoribonuclease of the RNase III family. One strand of the siRNA is loaded onto the AGO2RISC (Argonaute family protein 2-RNA-induced silencing complex) complex to mediate the degradation of $\mathrm{TE}$ transcripts with complementary sequence (Fig. 1a). The siRNA pathway operates in both soma and germ line. In the piRNA pathway, transcripts of piRNA-encoding genes clustered in the genome are processed by an endonuclease (Zucchini in Drosophila) into primary piRNA fragments (Fig. 1b). The primary piRNA is then loaded into the Aub (Aubergine) or Piwi protein to mediate the degradation of the TE transcript with a complementary sequence. Fragments of the degraded TE mRNA are loaded onto the AGO3 complex to mediate the generation of the secondary piRNA from a piRNA cluster transcript in a "ping-pong" amplification cycle [33]. Although the piRNA pathway operates predominantly in the germ line, only some specific somatic cells (e.g., stem cells and tumorous cells) have the capacity to express piwi genes and Piwi-interacting RNAs, suggesting somatic functions of the pathway in tissue regeneration and possibly cancer [34].

The piRNA pathways can also repress TE activity at the transcriptional level through RNA-mediated chromatin modification collectively called RNA-mediated epigenetic silencing. piRNAs not only promote degradation of TE mRNA, but also they can direct the recruitment of chromatin modifying factors to specific loci $[35,36]$.

\section{Changes in chromatin structure and TE activity during ageing}

Epigenetic changes influencing TE activity can be uniformly observed during ageing. For example, the murine intracisternal A-particle (IAP) retrotransposon has been found to become active upon ageing, and this change is associated with a progressive demethylation of the IAP promoter during the lifespan [37]. DNA methylation in humans also decreases as the individual ages [29]. A significant decline in average Alu (the most common SINE in primates) methylation over the lifespan was detected; age is thus negatively associated with methylation levels of Alu sequences [38]. Furthermore, whole-genome bisulfite sequencing in humans revealed that the centenarian DNA has significantly lower methylation content, as compared with the newborn DNA [39]. Together, these observations may reveal a general epigenetic process that could account for a series of events associated with ageing. Indeed, genomewide methylation profiles were recently used to quantify individual ageing rates in humans [22]. 
a

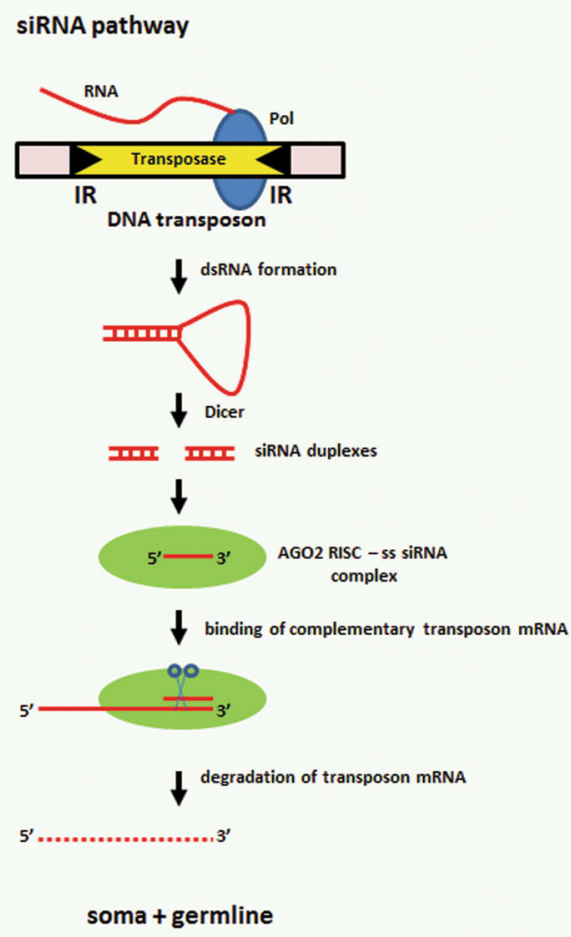

b piRNA pathway

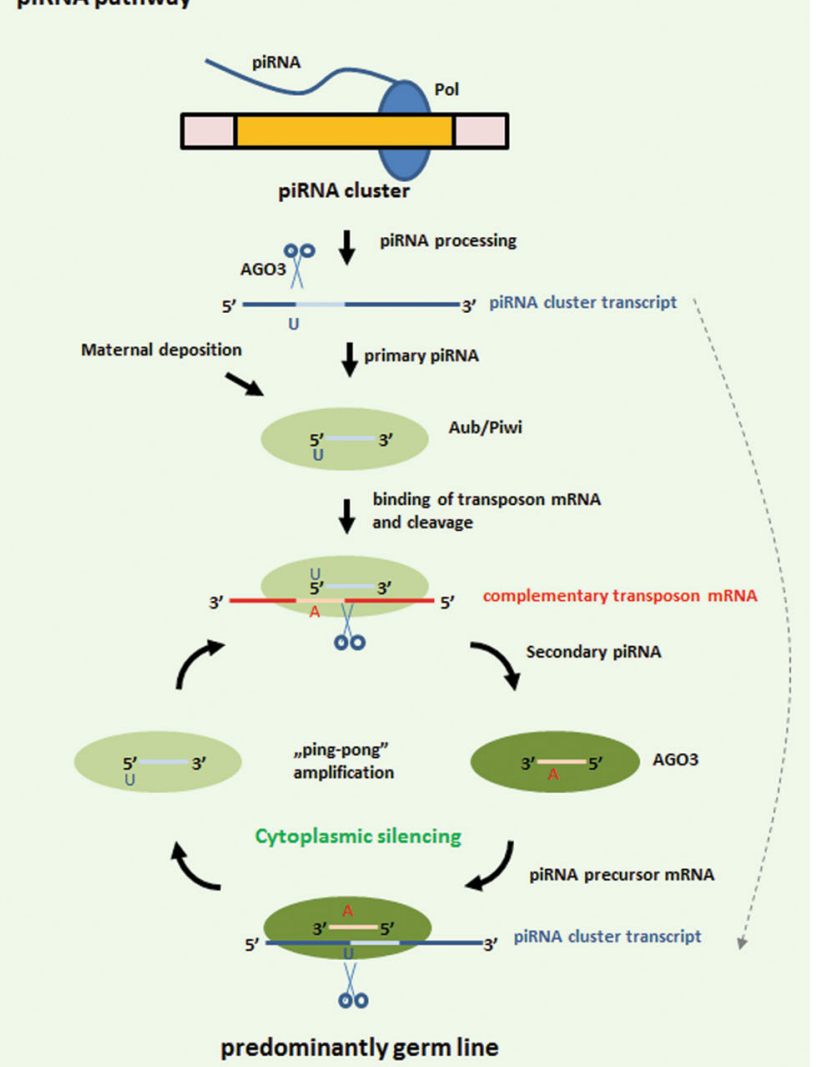

cluster that contains sequences of transposon origin. The primary piRNA is processed into 26-31 nt-long mature piRNAs (light blue) with uracil (U) at the $5^{\prime}$ end. The piRNA fragment binds an Argonaute family protein, Aubergine/Piwi (Aub/Piwi), and then is directed to a transposon transcript that is complementary to its sequence. Endonucleolytic cleavage of the transposon mRNA [at $10 \mathrm{nt}$ upstream of an adenine (A) whose position corresponds to the $U$ site of the mature piRNA] produces a secondary sense transposon piRNA, which associates with the Argunaute 3 (AGO3) protein. This complex is targeted to another piRNA cluster transcript that is endonucleotically cleaved at a $\mathrm{U}$ that corresponds to the A site of the sense transposon piRNA (the dashed, grey arrow), thereby generating a secondary piRNA fragment. The latter binds again an Aub/piwi protein and is directed to a transposon transcript. This so-called "ping-pong" amplification cycle of piRNAs destructs eventually the transcripts of those transposons that have been inserted into the piRNA cluster

of ageing in C. elegans revealed that only less than $1 \%$ of the genome shows significant changes in transcript levels as the organism ages [42]. Among these genes, expression of certain transposases markedly increases in older worms. In addition, somatic excision of Tc1, a DNA transposon in C. elegans, increases by more than 14 -fold during the organism's lifespan [43]. In an inbred D. melanogaster line, a significant age dependence of the transposition rate of the retrotransposon copia was documented [44]. Consistent with these findings, reverse transcriptase inhibitors caused 
retardation of ageing in this species [45]. In addition, it was recently found that several TEs were highly active in the Drosophila brain during normal ageing, suggesting that TE activation with age contributes to neuronal decline [46]. In humans, somatic expression of LINE1 elements has also been widely detected, and associated with the induction of DNA damage [47]. In the adult human brain, somatic retrotransposition reshapes the genetic circuitry in an individual pattern, underlying various pathological processes at advanced ages [48]. Senescence-associated somatic expression of LINE1 elements has also been widely detected [49]. Moreover, repression of LINE1 by SIRT6 into transcriptionally inactive heterochromatin fails to occur during the course of ageing [50]. Together, these data show that genetic damage generated by TE mobilisation in somatic cells may be a characteristic feature of ageing. Thus, TEs may have an important, suicidal role in age-related genomic instability [51-53].

\section{Somatic activity of the Piwi-piRNA pathway and its potential role in extreme longevity}

The Piwi-piRNA pathway effectively silences TE activity in the germ line, contributing considerably to genome integrity and immortality of this tissue. Here, we hypothesise that somatic expression of the pathway is responsible for the absence of the ageing phenotype in certain organisms, particularly lower eukaryotes. A Cnidarian, the freshwater hydra Hydra vulgaris, exhibits an almost unlimited regeneration capacity and immortality [54]. Its adult body largely consists of populations of stem cells with an unlimited proliferating and self-renewal capacity. These types of hydrozoan somatic cells are characterised by the abundant expression of Piwi proteins and Piwi-interacting RNAs [55, 56], suggesting low levels of TE activity in their genome. Another Cnidarian, the jellyfish T. nutricula, is also regarded as an immortal organism, as the sexually mature adult is able to transform itself back into a postlarval polyp stage, and repeat this cycle indefinitely [57]. Somatic cells of the closely related hydrozoan Podocoryne carnea, which can also alternate between the mature medusa and post-larval polyp stages, accumulate Piwi-like proteins (Cniwi) in somatic cells during all developmental stages [58]. This organism is likewise capable of continuously renewing its tissues. Considering that these Cnidarians are subjected to the same external DNA damaging factors as all other eukaryotic organisms, and that their DNA repair systems are not known to exhibit extraordinary effectiveness, we suggest that the activity of the Piwi-piRNA system is the cause of the non-ageing phenotype of their soma. In addition, some planarians (flatworms) display an extraordinary ability to regenerate lost body parts [59]. This phenomenon is used in asexual reproduction: the animal detaches its tail ends and each half regrows the lost parts by regeneration. During the process, adult stem cells divide and differentiate, and their activities are functionally associated with Piwi-like proteins [60]. As they have an apparently limitless regenerative capacity, planarians are considered to be effectively immortal. The amphibian Mexican axolotl also represents an animal species that lives unusually long (up to 25 years). In this organism, abundant activation of germ line-specific Piwi genes in the soma, especially in the wound epidermis, is required for injury-induced effective regeneration of limbs [61]. Thus, somatic activity of Piwi proteins and piRNAs is likely to contribute to increased longevity and regeneration capacity in these organisms.

\section{TE activity and the mechanism of ageing}

It has been widely accepted that ageing is associated with the progressive, lifelong accumulation of unrepaired cellular damage $[1,2]$. Cells respond to molecular stress by activating various defence mechanisms and eventually by dying. Massive levels of cell loss then lead to tissue deterioration and, eventually, to organismal death [62].

The germ line, cancer cells and certain Cnidaria are considered to be effectively immortal. They are also subjected to ionising radiation, harmful factors generated by their metabolism, or high temperature and oxidative stress-yet they do not show any signs of ageing. These immortal systems all share the activity of the Piwi-piRNA system whose main function is to silence TEs. Thus, we suggest that ageing is primarily caused by transpositionassociated genomic instability. Indeed, suppression of Alu by RNA interference in aged adult stem cells can reverse the senescent phenotype and reinstat the cells' self-renewing properties [63]. Other factors causing molecular damage do not influence the rate of ageing to a great extent, as the damage is either repaired, or the damaged cell is eliminated from the tissue through cell loss (Fig. 2).

Mutations induced by physical and chemical mutagens occur independently from TEs (biological mutagens) in both germ line and somatic cells, but the majority of these are repaired by effective molecular mechanisms, which include DNA repair pathways, molecular chaperones, autophagy and the ubiquitin-proteasome system (Fig. 2a-c). These cell repair mechanisms are likely to be equally effective in the soma and germ line, but they do operate with some imperfection. This imperfection, however, is inconsequential, as the damaged cells are eliminated at the population level (microevolution) [6]. The primary difference is that in the germ line, the TEs are largely silenced by the Piwi-piRNA pathway; while in the soma, TEs become 


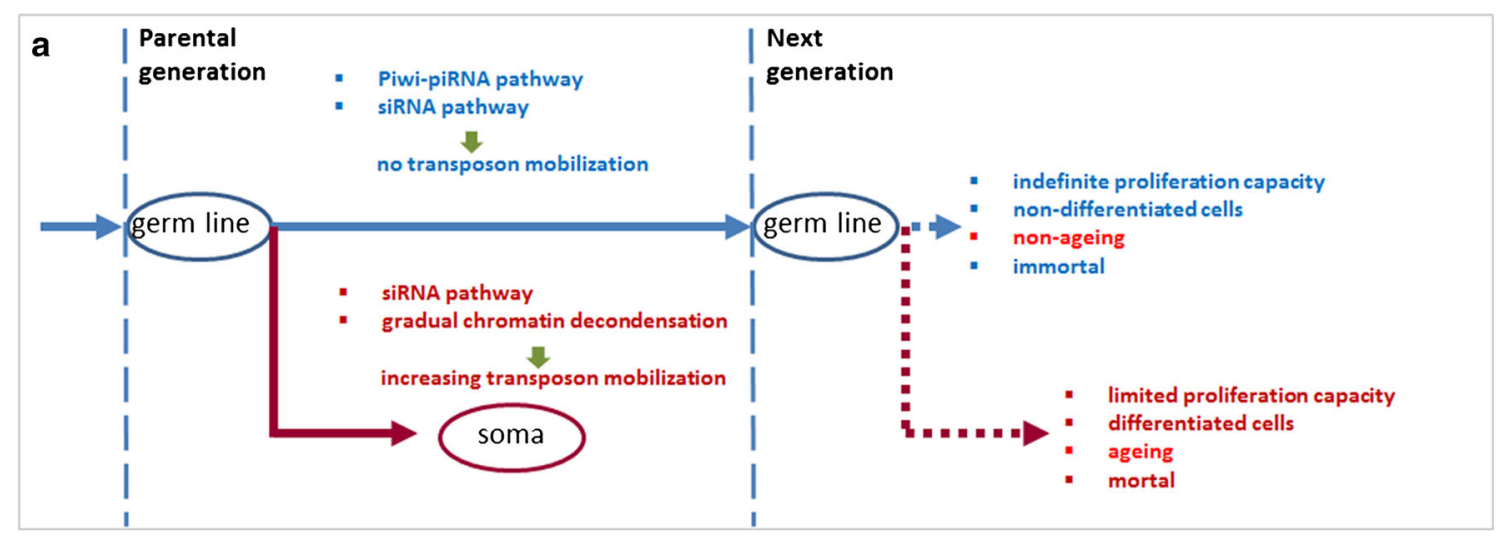

\begin{tabular}{|c|c|}
\hline $\left.\begin{array}{l}\text { b } \quad \text { Germ line } \\
\text { metabolism, radiation, } \ldots \rightarrow \text { ROS, DNA damage, } \ldots \rightarrow \text { cellular damage } \rightarrow \text { repair/cleaning } \\
\text { no transposon activity }\end{array}\right\}$ & $\begin{array}{l}\text { damaged cells are } \\
\text { selected out at the } \rightarrow \text { non-ageing } \\
\text { population level }\end{array}$ \\
\hline $\begin{array}{l}\text { Soma } \\
\text { metabolism, radiation, } \ldots \rightarrow \text { ROS, DNA damage, } \ldots \rightarrow \text { cellular damage } \rightarrow \text { repair/cleaning } \\
\text { transposon activity }\end{array}$ & $\begin{array}{l}\text { at advanced ages, } \\
\text { damaged cells are not } \\
\text { selected out at the } \rightarrow \text { ageing } \\
\text { population level }\end{array}$ \\
\hline
\end{tabular}

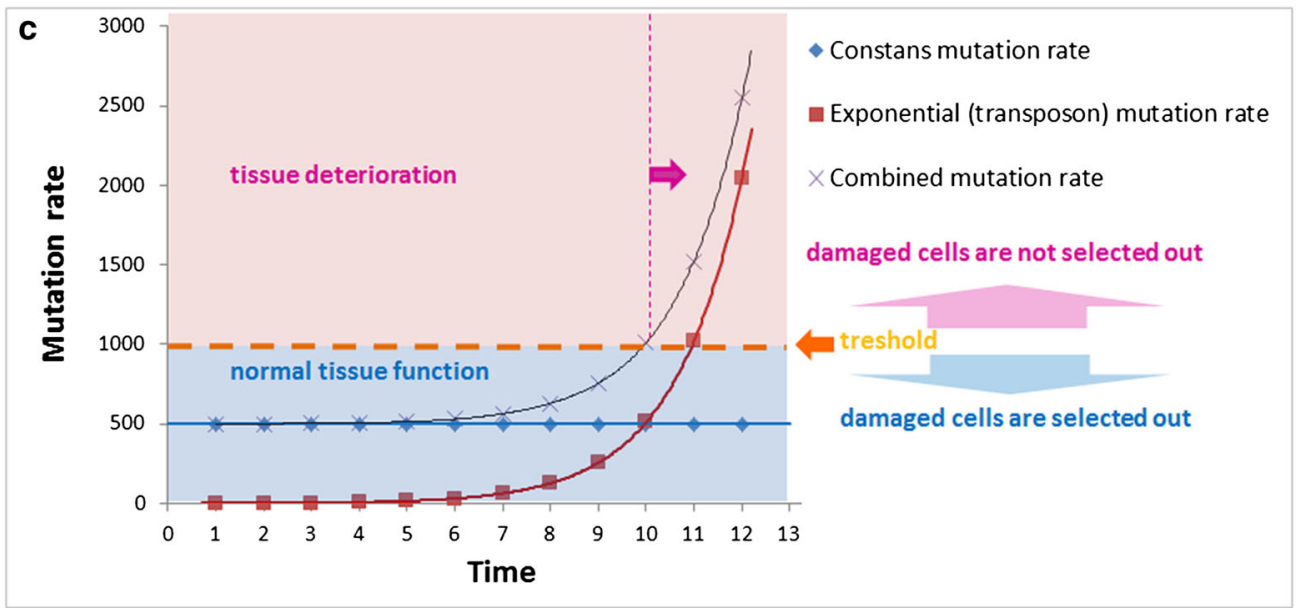

Fig. 2 Transposon activity primarily causes ageing in the soma. a In the germ line, the Piwi-piRNA system effectively silences transposons. Due to the lack of transposon mutagenesis, the germ line genome remains constantly stable. As a consequence, the germ line is essentially immortal. The Piwi-piRNA system does not operate in the soma (except from tumour and some stem cells). Gradual DNA demethylation and decrease in global heterochromatin state (chromatin decondensation) over the lifespan stimulate transposon mobilisation, leading to genome instability. As a result, the soma undergoes an age-related deterioration. b Both soma and germ line encounter various environmental and molecular stress factors (physical and chemical mutagens, ROS, high temperatures, etc.) that lead to the generation of cellular damage. Cellular damage can be removed by the repair (e.g., DNA repair pathways) and self-cleaning (e.g., autophagy) mechanisms. If damage is not eliminated, the affected cells are effectively selected out from the tissue (population) via microevolution until a given threshold. The remaining undamaged

progressively active during the lifespan. Replicative transposition is self-duplicating, enabling the number of retrotransposon-induced mutations to grow exponentially cells maintain tissue function. Over the threshold, due to the progressive accumulation of transposon insertions, abundant cell loss compromises tissue function. In the germ line, transposons are silenced, so the mutation rate is constant in time. c Unrepaired mutations caused by chemical or physical agents arise in both soma and germ line at a nearly constant rate during the lifespan of a given organism. In the example, this translates to 500 unrepaired, damaged cells in a single unit of time (purple line). The "fitness" of the cell containing the unrepaired mutation diminishes, allowing undamaged cells to overgrow it (microevolution). The population's selection capability (yellow dashed line) allows for 1000 damaged cells to be removed in a unit of time, meaning that 0-1000 damaged cells may be selected out (blue area) in that timeframe. However, mutations generated by replicative transposition occur with an exponential rate as the organism ages (green line). As a result, the number of unrepaired damaged cells increases at a rate surpassing the population's selection rate, so the damaged cells cannot all be selected

in the somatic genome over time, and explaining why the mortality rate rises exponentially throughout adult life in most animal species (Fig. 2c). Since TEs constitute a 
significant portion of eukaryotic genomes, the mutagenic effect of their activity may be considerable [46, 50, 63], thereby providing a plausible explanation for the difference in mutation rates between somatic and germ line genomes. Thus, TE activity may be the main factor in ageing. In the germ line, the mutation rate is constant due to the silenced TEs, in contrast to the exponential rate of TE-derived mutagenesis in the soma. As a result of the exponential mutation rate, damaged somatic cells cannot be eliminated after a while, since the rate of mutation surpasses the rate of elimination, a process that manifests in ageing (Fig. 2b, c). Note that factors modulating the accumulation of cellular damage generally affect transposition as well. For instance, caloric restriction leads to attenuation of metabolism (including respiration) and, through reduced transcription and cell proliferation rate, lowered transposition activity [64]. The constant mutation rate of the germ line does not exceed the elimination rate, allowing all damaged cells to be eliminated from the population through cell loss or early embryo death (Fig. 2c) (in $C$. elegans, for example, nearly half of the germ cells undergo apoptosis [65]). This is why mutant or damaged cells cannot accumulate in the germ line, allowing it to attain the quality of immortality.

Acknowledgments This work was supported by the grants OTKA (Hungarian Scientific Research Fund) NK78012 and MEDinPROT Protein Science Research Synergy Program (provided by the Hungarian Academy of Sciences) to T. V. The authors are grateful to Daniel Sturm for his proofreading and translation assistance.

Conflict of interest The authors declare no competing financial interest.

\section{References}

1. Kenyon CJ (2010) The genetics of ageing. Nature 464(7288): 504-512. doi:10.1038/nature08980

2. López-Otín C, Blasco MA, Partridge L, Serrano M, Kroemer G (2013) The hallmarks of aging. Cell 153(6):1194-1217. doi:10. 1016/j.cell.2013.05.039

3. Vellai T, Takacs-Vellai K, Sass M, Klionsky DJ (2009) The regulation of aging: does autophagy underlie longevity? Trends Cell Biol 19(10):487-494. doi:10.1016/j.tcb.2009.07.007

4. Kirkwood TB (2008) A systematic look at an old problem. Nature 451(7179):644-647. doi:10.1038/451644a

5. Koubova J, Guarente L (2003) How does calorie restriction work? Genes Dev 17(3):313-321. doi:10.1101/gad.1052903

6. Kirkwood TB, Proctor CJ (2003) Somatic mutations and ageing in silico. Mech Ageing Dev 124(1):85-92

7. Dillin A, Hsu AL, Arantes-Oliveira N, Lehrer-Graiwer J, Hsin H, Fraser AG, Kamath RS, Ahringer J, Kenyon C (2002) Rates of behavior and aging specified by mitochondrial function during development. Science 298(5602):2398-2401. doi:10.1126/science. 1077780

8. Narayanan L, Fritzell JA, Baker SM, Liskay RM, Glazer PM (1997) Elevated levels of mutation in multiple tissues of mice deficient in the DNA mismatch repair gene Pms2. Proc Natl Acad Sci USA 94(7):3122-3127

9. Vijg J (2000) Somatic mutations and aging: a re-evaluation. Mutat Res 447(1):117-135

10. Degtyareva NP, Greenwell P, Hofmann ER, Hengartner MO, Zhang L, Culotti JG, Petes TD (2002) Caenorhabditis elegans DNA mismatch repair gene msh-2 is required for microsatellite stability and maintenance of genome integrity. Proc Natl Acad Sci USA 99(4):2158-2163. doi:10.1073/pnas.032671599

11. Harley CB, Vaziri H, Counter CM, Allsopp RC (1992) The telomere hypothesis of cellular aging. Exp Gerontol 27(4): 375-382

12. Tomas-Loba A, Flores I, Fernandez-Marcos PJ, Cayuela ML, Maraver A, Tejera A, Borras C, Matheu A, Klatt P, Flores JM, Vina J, Serrano M, Blasco MA (2008) Telomerase reverse transcriptase delays aging in cancer-resistant mice. Cell 135(4):609-622. doi:10.1016/j.cell.2008.09.034

13. Raices M, Maruyama H, Dillin A, Karlseder J (2005) Uncoupling of longevity and telomere length in C. elegans. PLoS Genet 2005:e30. doi:10.1371/journal.pgen.0010030.eor

14. Lynch M (2010) Evolution of the mutation rate. Trends Genet 26(8):345-352. doi:10.1016/j.tig.2010.05.003

15. Vijg J (2014) Somatic mutations, genome mosaicism, cancer and aging. Curr Opin Genet Dev 26:141-149. doi:10.1016/j.gde.2014. 04.002

16. Curran SP, Wu X, Riedel CG, Ruvkun G (2009) A soma-to-germ line transformation in long-lived Caenorhabditis elegans mutants. Nature 459(7250):1079-1084. doi:10.1038/nature08106

17. Kouzarides $\mathrm{T}$ (2007) Chromatin modifications and their function. Cell 128(4):693-705. doi:10.1016/j.cell.2007.02.005

18. Tsurumi A, Li WX (2012) Global heterochromatin loss: a unifying theory of aging? Epigenetics 7(7):680-688. doi:10.4161/ epi.20540

19. Villeponteau B (1997) The heterochromatin loss model of aging. Exp Gerontol 32(4-5):383-394

20. Larson K, Yan SJ, Tsurumi A, Liu J, Zhou J, Gaur K, Guo D, Eickbush TH, Li WX (2012) Heterochromatin formation promotes longevity and represses ribosomal RNA synthesis. PLoS Genet 8(1):e1002473. doi:10.1371/journal.pgen.1002473

21. Lin SJ, Defossez PA, Guarente L (2000) Requirement of NAD and SIR2 for life-span extension by calorie restriction in Saccharomyces cerevisiae. Science 289(5487):2126-2128

22. Hannum G, Guinney J, Zhao L, Zhang L, Hughes G, Sadda S, Klotzle B, Bibikova M, Fan JB, Gao Y, Deconde R, Chen M, Rajapakse I, Friend S, Ideker T, Zhang K (2012) Genome-wide methylation profiles reveal quantitative views of human aging rates. Mol Cell 49(2):359-367. doi:10.1016/j.molcel.2012.10.016

23. Cooney CA (1993) Are somatic cells inherently deficient in methylation metabolism? A proposed mechanism for DNA methylation loss, senescence and aging. Growth Dev Aging 57(4):261-273

24. Richardson B (2003) Impact of aging on DNA methylation. Ageing Res Rev 2(3):245-261

25. Liu L, Wylie RC, Andrews LG, Tollefsbol TO (2003) Aging, cancer and nutrition: the DNA methylation connection. Mech Ageing Dev 124(10-12):989-998

26. Mills RE, Bennett EA, Iskow RC, Luttig CT, Tsui C, Pittard WS, Devine SE (2006) Recently mobilized transposons in the human and chimpanzee genomes. Am J Hum Genet 78(4):671-679. doi:10.1086/501028

27. de Koning AP, Gu W, Castoe TA, Batzer MA, Pollock DD (2011) Repetitive elements may comprise over two-thirds of the human genome. PLoS Genet 7(12):e1002384. doi:10.1371/ journal.pgen.1002384

28. Lander ES, Linton LM, Birren B, Nusbaum C, Zody MC et al (2001) Initial sequencing and analysis of the human genome. Nature 409(6822):860-921. doi:10.1038/35057062 
29. Bollati V, Schwartz J, Wright R, Litonjua A, Tarantini L, Suh H, Sparrow D, Vokonas P, Baccarelli A (2009) Decline in genomic DNA methylation through aging in a cohort of elderly subjects. Mech Ageing Dev 130(4):234-239. doi:10.1016/j.mad.2008.12. 003

30. O'Donnell KA, Burns KH (2010) Mobilizing diversity: transposable element insertions in genetic variation and disease. Mobile DNA 1(1):21. doi:10.1186/1759-8753-1-21

31. Wicker T, Sabot F, Hua-Van A, Bennetzen JL, Capy P, Chalhoub B, Flavell A, Leroy P, Morgante M, Panaud O, Paux E, SanMiguel P, Schulman AH (2007) A unified classification system for eukaryotic transposable elements. Nat Rev Genet 8(12):973-982. doi: $10.1038 /$ nrg2 2165

32. Malone CD, Hannon GJ (2009) Small RNAs as guardians of the genome. Cell 136(4):656-668. doi:10.1016/j.cell.2009.01.045

33. Zamore PD (2010) Somatic piRNA biogenesis. EMBO J 29(19):3219-3221. doi:10.1038/emboj.2010.232

34. Ross RJ, Weiner MM, Lin H (2014) PIWI proteins and PIWIinteracting RNAs in the soma. Nature 505(7483):353-359. doi:10.1038/nature12987

35. Moazed D (2009) Small RNAs in transcriptional gene silencing and genome defence. Nature 457(7228):413-420. doi:10.1038/ nature 07756

36. Luteijn MJ, Ketting RF (2013) PIWI-interacting RNAs: from generation to transgenerational epigenetics. Nat Rev Genet 14(8):523-534. doi:10.1038/nrg3495

37. Barbot W, Dupressoir A, Lazar V, Heidmann T (2002) Epigenetic regulation of an IAP retrotransposon in the aging mouse: progressive demethylation and de-silencing of the element by its repetitive induction. Nucl Acids Res 30(11):2365-2373

38. Jintaridth P, Mutirangura A (2010) Distinctive patterns of agedependent hypomethylation in interspersed repetitive sequences. Physiol Genomics 41(2):194-200. doi:10.1152/physiolgenomics. 00146.2009

39. Heyn H, Li N, Ferreira HJ, Moran S, Pisano DG, Gomez A, Diez J, Sanchez-Mut JV, Setien F, Carmona FJ, Puca AA, Sayols S, Pujana MA, Serra-Musach J, Iglesias-Platas I, Formiga F, Fernandez AF, Fraga MF, Heath SC, Valencia A, Gut IG, Wang J, Esteller M (2012) Distinct DNA methylomes of newborns and centenarians. Proc Natl Acad Sci USA 109(26):10522-10527. doi:10.1073/pnas.1120658109

40. Maxwell PH, Burhans WC, Curcio MJ (2011) Retrotransposition is associated with genome instability during chronological aging. Proc Natl Acad Sci USA 108(51):20376-20381. doi:10.1073/ pnas. 1100271108

41. Bertrand H, Chan BS, Griffiths AJ (1985) Insertion of a foreign nucleotide sequence into mitochondrial DNA causes senescence in Neurospora intermedia. Cell 41(3):877-884

42. Lund J, Tedesco P, Duke K, Wang J, Kim SK, Johnson TE (2002) Transcriptional profile of aging in C. elegans. Curr Biol 12(18):1566-1573

43. Egilmez NK, Shmookler Reis RJ (1994) Age-dependent somatic excision of transposable element Tc1 in Caenorhabditis elegans. Mutat Res 316(1):17-24

44. Filatov DA, Morozova TV, Pasyukova EG (1998) Age dependence of the copia transposition rate is positively associated with copia transcript abundance in a Drosophila melanogaster isogenic line. Mol Gen Genet 258(6):646-654

45. Driver CJ, Vogrig DJ (1994) Apparent retardation of aging in Drosophila melanogaster by inhibitors of reverse transcriptase. Ann N Y Acad Sci 717:189-197

46. Li W, Prazak L, Chatterjee N, Gruninger S, Krug L, Theodorou D, Dubnau J (2013) Activation of transposable elements during aging and neuronal decline in Drosophila. Nat Neurosci 16(5):529-531. doi:10.1038/nn.3368
47. Belancio VP, Roy-Engel AM, Pochampally RR, Deininger P (2010) Somatic expression of LINE-1 elements in human tissues. Nucl Acids Res 38(12):3909-3922. doi:10.1093/nar/gkq132

48. Baillie JK, Barnett MW, Upton KR, Gerhardt DJ, Richmond TA, De Sapio F, Brennan PM, Rizzu P, Smith S, Fell M, Talbot RT, Gustincich S, Freeman TC, Mattick JS, Hume DA, Heutink P, Carninci P, Jeddeloh JA, Faulkner GJ (2011) Somatic retrotransposition alters the genetic landscape of the human brain. Nature 479(7374):534-537. doi:10.1038/nature10531

49. De Cecco M, Criscione SW, Peckham EJ, Hillenmeyer S, Hamm EA, Manivannan J, Peterson AL, Kreiling JA, Neretti N, Sedivy JM (2013) Genomes of replicatively senescent cells undergo global epigenetic changes leading to gene silencing and activation of transposable elements. Aging Cell 12(2):247-256. doi:10. 1111/acel.12047

50. Van Meter M, Kashyap M, Rezazadeh S, Geneva AJ, Morello TD, Seluanov A, Gorbunova V (2014) SIRT6 represses LINE1 retrotransposons by ribosylating KAP1 but this repression fails with stress and age. Nat Commun 5:5011. doi:10.1038/ncomms 6011

51. Fontana A (2010) A hypothesis on the role of transposons. Biosystems 101(3):187-193. doi:10.1016/j.biosystems.2010.07. 002

52. Murray V (1990) Are transposons a cause of ageing? Mutat Res 237(2):59-63

53. Nikitin AG, Shmookler Reis RJ (1997) Role of transposable elements in age-related genomic instability. Genetical Res 69(3):183-195

54. Martinez DE (1998) Mortality patterns suggest lack of senescence in hydra. Exp Gerontol 33(3):217-225

55. Watanabe H, Hoang VT, Mattner R, Holstein TW (2009) Immortality and the base of multicellular life: lessons from cnidarian stem cells. Sem Cell Dev Biol 20(9):1114-1125. doi:10.1016/j.semcdb.2009.09.008

56. Juliano CE, Reich A, Liu N, Gotzfried J, Zhong M, Uman S, Reenan RA, Wessel GM, Steele RE, Lin H (2014) PIWI proteins and PIWI-interacting RNAs function in Hydra somatic stem cells. Proc Natl Acad Sci USA 111(1):337-342. doi:10.1073/pnas. 1320965111

57. Carla EC, Pagliara P, Piraino S, Boero F, Dini L (2003) Morphological and ultrastructural analysis of Turritopsis nutricula during life cycle reversal. Tissue Cell 35(3):213-222

58. Seipel K, Yanze N, Schmid V (2004) The germ line and somatic stem cell gene Cniwi in the jellyfish Podocoryne carnea. Int $\mathrm{J}$ Dev Biol 48(1):1-7

59. Sanchez Alvarado A (2006) Planarian regeneration: its end is its beginning. Cell 124(2):241-245. doi:10.1016/j.cell.2006.01.012

60. Rossi L, Salvetti A, Lena A, Batistoni R, Deri P, Pugliesi C, Loreti E, Gremigni V (2006) DjPiwi-1, a member of the PAZPiwi gene family, defines a subpopulation of planarian stem cells. Dev Genes Evol 216(6):335-346. doi:10.1007/s00427-0060060-0

61. Zhu W, Pao GM, Satoh A, Cummings G, Monaghan JR, Harkins TT, Bryant SV, Randal Voss S, Gardiner DM, Hunter T (2012) Activation of germ line-specific genes is required for limb regeneration in the Mexican axolotl. Dev Biol 370(1):42-51. doi:10.1016/j.ydbio.2012.07.021

62. van Deursen JM (2014) The role of senescent cells in ageing. Nature 509(7501):439-446. doi:10.1038/nature13193

63. Wang J, Geesman GJ, Hostikka SL, Atallah M, Blackwell B, Lee E, Cook PJ, Pasaniuc B, Shariat G, Halperin E, Dobke M, Rosenfeld MG, Jordan IK, Lunyak VV (2011) Inhibition of activated pericentromeric SINE/Alu repeat transcription in senescent human adult stem cells reinstates self-renewal. Cell Cycle 10(17):3016-3030 
64. De Cecco M, Criscione SW, Peterson AL, Neretti N, Sedivy JM, Kreiling JA (2013) Transposable elements become active and mobile in the genomes of aging mammalian somatic tissues. Aging 5(12):867-883
65. Gumienny TL, Lambie E, Hartwieg E, Horvitz HR, Hengartner MO (1999) Genetic control of programmed cell death in the Caenorhabditis elegans hermaphrodite germ line. Development 126(5):1011-1022 